\title{
PSICO-EDUCAÇÃO: UM PROJETO VISANDO AUMENTAR A EFICIÊNCIA DAS INTERVENÇÕES SOCIAIS JUNTO ÀS CRIAN- ÇAS E ADOLESCENTES EM SITUAÇÃO DE RISCO PSICO- SOCIAL EM RIBEIRÃO PRETO-S.P.
}

Marina Rezende Bazon*

\section{RESUMO}

Este texto relata a experiência riberäopretana de convênio entre o governo municipal e entidades não-governamentais na busca de meios visando qualificar a prática desenvolvida nos serviços destinados às crianças e adolescentes em situação de risco psicossocial do município. Neste sentido, destaca-se a assessoria recebida do Centro de Psicoeducação do Québec, Canadá, cujo aporte teórico-metodológico possibilitou discutir, com base em parâmetros científicos, as possibilidades e os limites da rede de apoio social em Ribeirão Preto.

\section{INTRODUÇÃO}

Ribeirão Preto, uma cidade de aproximadamente 450 mil habitantes (IBGE, 1991), possui características semelhantes aos grandes centros urbanos brasileiros, onde a convivência entre a miséria, de um lado, e um elevado nível sócio-econômico de outro, incorre para o surgimento de contradições sociais importantes, propiciando vivências violentas, de inúmeras ordens.

Esse contexto de contradições sociais é determinante da existência de fatores relacionados ao stress, prejudiciais ao desenvolvimento psicológico e social da população em geral. Leis e normas vividas de maneira inconsistente, fácil acesso às drogas na comunidade, rede de suporte social (lazer, educação e saúde) deficitária e desarticulada, são alguns dos fatores, no âmbito social, que colocam em risco a qualidade de vida das pessoas (Lemay, 1996).

Diante desta situação, os indivíduos oriundos das camadas médias e altas da população recorrem, geralmente, a mecanismos particulares de proteção e suporte, acionando uma rede de apoio social privada.

Já as classes populares, que vivem mais diretamente as intercorrências da pobreza - apontada pela literatura especializada como um fator de risco contundente ao desenvolvimento humano (Hutz, Koller e Bandeira, 1996, p.

* Mestre em Psico-Educação e Docente do Departamento de Psicologia e Educação da Faculdade de Filosofia, Ciências e Letras da USP-Ribeirão Preto 
80) - servem-se majoritariamente dos recursos oferecidos pelos órgãos públicos, que também sofrem da necessidade de maiores investimentos.

É fato que o município de Ribeirão Preto encontra-se há anos buscando ampliar e articular sua rede de atendimento dirigida à população em situação de maior risco pessoal e social. Apesar dos programas e serviços desenvolvidos ainda serem insuficientes em número, e apresentarem lacunas no que tange a determinadas necessidades identificadas na cidade, pode-se afirmar que grande parte dos esforços governamentais e não governamentais voltam-se no sentido de consolidar uma rede de apoio social ampla e articulada.

Na linha da análise mais geral realizada para o âmbito nacional, podemos prever que a próxima etapa que se impõe a Ribeirão Preto consiste em trabalhar a "reforma das instituições e na melhoria da atenção direta", reestruturação que não pode deixar de ser verdadeiramente profunda, passando necessariamente pela qualificação do pessoal (Mendez, E.G. \& Costa, A.C.G. da, 1994, p.61).

No momento em que nos encontramos, a qualidade e a eficiência dos serviços não foram muito bem avaliadas do ponto de vista científico, mesmo por que a ação implementada no interior destes estabelecimentos encontra-se pouco embasada em conhecimentos científicos. As estratégia de intervenção utilizadas não se encontram suficientemente sistematizadas, dificultando suas análises, revisões e correções. Pode-se, contudo, dizer que os serviços acabam por desempenhar, basicamente, uma função de tipo assistencialista, propondo guarda e abrigo temporários, subtilizando "o tempo e o espaço", do ponto de vista educacional, para a clientela que está a sua disposição. Os programas propostos às classes populares tendem a "tutelar" seus beneficiários através de uma política de linha compensatória (leite, cesta básica, renda mínima, etc.) que, em essência, negam-lhes autonomia e direitos de cidadania (Takashima, 1997).

Com relação ao pessoal que faz o "corpo a corpo" no cotidiano dos serviços, esse possui em geral pouca formação específica e instrumental que o capacite a lidar com problemáticas algumas vezes bastante complexas, que caracterizam a clientela.

Por sua vez, o chamado corpo técnico, composto de profissionais de nível universitário (assistentes sociais, psicólogos, pedagogos e terapeutas ocupacionais em sua maioria), cujo o mandato é, a grosso modo, embasar, orientar e supervisionar a prática dos monitores-educadores, encontra-se em grande parte distanciado dos eventos e exigências que o cotidiano, ou melhor, a rotina 
dos serviços impõe.

Por outro lado, as condições materiais desfavoráveis, relativa tanto ao contexto de intervenção, quanto ao meio de origem da clientela, limitam o alcance das ações empreendidas pelos profissionais e a eficácia das estratégias pertinentes a cada área de atuação.

Tendo em vista esse quadro, e objetivo de aumentar a qualidade dos serviços existentes na cidade, a Prefeitura Municipal de Ribeirão Preto estabeleceu um convênio, entre 1995 e 1996, com um clube rotariano (Rotary Club Ribeirão Preto-Norte) e uma organização não-governamental (Organização Comunitária Santo Antônio Maria de Claret), regulamentado pela Lei Municipal No 7187/95, que possibilitou contar com a assessoria de um Centro de Formação Canadense (Centro de Psico-Educação do Québec), filiado à Universidade de Montréal, num projeto visando discutir os limites e as possibilidades da rede ribeirãopretana de atendimento, tendo por referência o modelo teórico-prático desenvolvido no Canadá.

Vale destacar que o modelo canadense apoia-se em conceitos e elaborações estudadas sob o título de Psico-Educação e que tal braço da ciência vem se desenvolvendo e consolidando desde a década de 50 naquele país.

Desde o princípio, o modelo psicoeducativo desenvolveu-se num contexto de extrema colaboração entre professores e educadores vinculados à prática cotidiana de Centros de Atendimento à Infância e Adolescência. Assim, pode-se afirmar que a abordagem psicoeducativa caracteriza-se por uma integração consistente entre conhecimentos teórico-científicos e a aplicação dos mesmos - o que parece garantir a eficiência e a qualidade dos serviços no Canadá, apontado como um dos melhores do mundo (Renou, 1989; Renou, 1991; Le Blanc, 1995a).

Atualmente a Psico-Educação está organizada dentro das universidades, em departamentos autônomos responsáveis por formações a nível de graduação e pós-graduação.

\section{A PSICO-EDUCAÇÃO: CONCEITOS DE BASE}

O nascimento da Psico-Educação resulta de um processo de modernização da sociedade canadense, quando o pensamento humanista começa a influenciar o funcionamento das instituições naquele país. Não se pode dissociar sua evolução da História das intervenções sócio-educativas junto a indivíduos em dificuldades a nível do desenvolvimento psicossocial.

Num período anterior à Psico-Educação, este tipo de trabalho resumia-se à internação de crianças e adolescentes em grandes instituições, onde 
inúmeras problemáticas eram confundidas. Essas instituições eram geralmente superlotadas e o quadro de funcionários não possuía nenhuma qualificação. $O$ regime era o de grande agrupamento de indivíduos onde a atenção individual era impossível, e a disciplina estrita se fazia necessária, assim como a punição era empregada corriqueiramente como método educacional. Além disso, buscava-se a "recuperação" através da ocupação por meio de trabalhos manuais e, na melhor das hipóteses, da profissionalização dos indivíduos. A mentalidade da época (final dos anos 40) fundamentava-se fortemente em concepções assistencialistas, de caráter confessional (Renou, 1989).

Com a Psico-Educação inicia-se um processo de modificação na organização das instituições, sendo que a estrutura e o funcionamento passam a ser revisados em função das necessidades e características identificadas na clientela. A Psico-Educação propicia assim: a elaboração de instrumentos pedagógicos apropriados à implementação de projetos educacionais específicos; a pesquisa visando o apoio científico à ação educativa; e uma formação específica para a atuação no cotidiano das instituições, buscando qualificar os serviços (Renou, 1989).

Se nos primórdios a prática psico-educativa está intimamente vinculada às instituições de tipo internato, ao longo dos anos ela estendeu-se e especializou-se na aplicação do modelo em serviços "mais abertos" e comunitários. Neste sentido, o modelo passa a incluir, progressivamente, o ambiente natural dos indivíduos, uma vez que o meio começa a ser considerado, nas suas ações e reações, como um dos fatores relacionados às dificuldades do indivíduo.

Deste modo, a Psico-Educação auxilia na concepção de uma rede integrada de serviços, denominada "Sistema em Cascata", onde privilegia-se as ações de prevenção e onde o internato é utilizado como o último dos recurso (Renou, 1991).

A nível conceitual, o modelo psicoeducativo fundamenta-se em dois postulados de base, a partir do qual decorre as concepções de meio de intervenção e de ação educativa: a) A visão de Ser Humano e b) $O$ potencial educacional do cotidiano "compartilhado" no dia-a-dia dos meios de intervenção.

No que tange a visão de Homem, e por extensão, a visão de serhumano em dificuldades, Le Blanc (1995b) coloca que o indivíduo, dentro desta perspectiva, é sempre considerado como um ser em constante desenvolvimento e cujo processo evolutivo inscreve-se em uma estreita relação de inter-influência entre ele e o ambiente. Além disso, o desenvolvimento humano dar-se-ia simultaneamente nos planos afetivo, cognitivo, social e físico-motor, cabendo à 
ação educativa especializada mediar as interações entre o indivíduo e o ambiente a fim de promover a atualização do desenvolvimento, em todo seu potencial.

No mais, dentro da perspectiva da Psico-Educação, considera-se que no cotidiano das instituições numerosas são as interações passíveis de influenciar o sujeito e de promover seu desenvolvimento, de tal modo que o adulto-educador, consciente do potencial educacional das vivências cotidianas (por mais banais que elas pareçam), demonstre grande competência na colocação de seus gestos e em suas ações frente ao indivíduo em dificuldades.

Neste sentido, o educador é figura central pois ele representa e "dá vida" ao ambiente que se concebe terapêutico e/ou educacional, cabendolhe então estabelecer e manter uma relação de ajuda e de acompanhamento através da vivência compartilhada de situações cotidianas, mediando também outras interações que o indivíduo venha estabelecer. Nesta visão, o educador é um agente de transformação NO e PELO evento cotidiano.

Nas palavras dos teóricos que deram início às elaborações conceituais em Psico-Educação, respectivamente Jeannine Guindon e Gilles Gendreau (citados em Lebon, 1996): "o educador é um profissional qualificado que se interessa essencialmente todos os aspectos da vida da criança. Ele cumpre seu papel profissional compartilhando os acontecimentos cotidianos da vida da criança e planejando os momentos de vida de modo a colocar diretamente em jogo o desenvolvimento psíquico, moral, social $e$ intelectual da criança", sendo que "a intervenção psicoeducativa inscreve-se na perspectiva de meio total e não existe insignificâncias em educação. Nenhuma presença é mais nobre que outra quando nos tornamos educadores no e pelo acontecimento".

\section{A PSICO-EDUCAÇÃO EM RIBEIRÃO PRETO}

A idéia fundamental do projeto de formação em Psico-Educação foi propiciar a profissionais, exercendo diversos níveis de responsabilidades em programas e serviços de Ribeirão Preto, a oportunidade de familiarizar-se com os conceitos e instrumentos da abordagem psicoeducativa de modo que pudessem conceber as possibilidades de sistematização das práticas empreendidas, bem como ressaltar a importância da articulação entre seus serviços.

Evidentemente, ao longo do processo de formação, em seus diferentes níveis, colocar-se-ia na pauta de discussões a pertinência do modelo para a nossa realidade, uma vez que ouvia-se com alguma freqüência que "o que serve para o Canadá não serve para o Brasil...”. Assim, o mesmo projeto proporcionaria a oportunidade de verificar essa questão, acreditando-se de an- 
temão que a relevância da Psico-Educação oriunda muito mais do fato dela propor elementos de reflexão e organização dos meios de intervenção, qualquer que ele seja, que do fato dela ditar normas de funcionamento e de intervenções. A experiência de Ribeirão Preto tornar-se-ia, então, um meio de validar o modelo para a nossa realidade.

Neste sentido, organizou-se um grupo de trinta profissionais, provenientes de vários serviços e programas, para receberem uma formação teórica objetivando sensibilizá-los à abordagem psicoeducativa e fornecer-lhes ferramentas (próprias à Psico-Educação) para refletirem sobre a prática.

No final desta formação, os participantes fizeram a seguinte avaliação: a) A composição de um grupo heterogêneo agradou-lhes pois permitiu que descobrissem o que cada um fazia, ou seja, suas posições na rede de serviços ribeirãopretana, constatando que poderiam tornar-se bem mais "fortes" trabalhando em conjunto; b) Com consequência, constataram a desarticulação ainda presente na rede, ressaltando a necessidade de organizarem os serviços destinados aos jovens; c) A dimensão metodológica da Psico-Educação interessou-lhes bastantes (esquema de análise e organização dos meios de intervenção, operações profissionais, técnicas de intervenção, trabalho em equipe, etc), embora reconhecessem a dificuldades de aplicá-la em suas práticas, considerando o grau de sistematização intrínseco em tal metodologia e a necessidade de uma formação mais aprofundada.

Num outro nível, organizou-se a aplicação do modelo psicoeducativo em duas instituições ribeirãopretanas, de modo que o processo ali experimentado se tornasse demonstrativo das idéias veiculadas pela Psico-Educação. Essas instituições foram a "Escola de Marcenaria", da Organização Comunitária Santo Antônio Maria de Claret, e o "Nosso Clubinho", da Sociedade Beneficente Evangélica de Ribeirão Preto, organizações essas não-governamentais, porém conveniadas com a prefeitura de Ribeirão Preto.

É importante dizer que a "Escola de Marcenaria" recebe diurnamente cerca de 100 adolescentes (50 em cada período), em horário alternado à escola regular, e visa prioritariamente a profissionalização da clientela. O "Nosso Clubinho" é uma casa abrigo onde podem residir 14 crianças, cujo encaminhamento tenha partido do Poder Judiciário ou do Conselho Tutelar.

Essa dimensão do projeto, desenvolvida nesses dois serviços, deuse ao longo de 15 meses, a tempo integral, tendo sido desenvolvido pela autora do presente artigo, com a supervisão e o auxílio de consultores do Centro de PsicoEducação do Québec. Vale ressaltar que a análise do processo e dos resultados dessa aplicação serão detalhados e discutidos em tese de doutoramento da autora no Programa de Pós-Graduação em Psicologia da 
Faculdade de Filosofia, Ciências e Letras da USP, em Ribeirão Preto.

No momento, pode-se destacar os objetivos gerais que foram visados a nível da implantação do modelo, tendo em vista a análise das necessidades destes Serviços.

Para a Escola de Marcenaria buscou-se:

a) Ajudar os educadores a ampliar seus conhecimentos referentes às necessidades socio-afetivas e às características psicológicas dos adolescentes da Escola de Marcenaria;

b) Ajudar os educadores a desenvolverem suas capacidades de "animação" na Escola, e suas capacidades de "utilização" dos elementos da vida cotidiana, numa perspectiva educativa;

c) Introduzir uma dimensão psicoeducativa nas atividades já existentes;

d) Enriquecer o programa com a introdução de atividades variadas, pertinentes às necessidades identificadas na clientela;

e) Melhorar o clima relacional (adulto/criança) da Escola;

f) Estimular os educadores a trabalhar em equipe.

No que diz respeito ao Nosso Clubinho, os objetivos gerais trabalhados foram:

a) Ajudar a equipe a aumentar seus conhecimentos sobre as necessidades e as características da clientela do Clubinho;

b) Ajustar a organização do meio de vida (Clubinho) em função das necessidades de desenvolvimento das crianças e adolescentes ali residentes;

c) Ajudar a equipe a tomar consciência do valor educativo do cotidiano compartilhado com as crianças e os adolescentes;

d) Levar os educadores a desenvolverem uma filosofia de intervenção que considere as forças e limites de cada criança;

e) Reativar o trabalho de orientação e acompanhamento junto às famílias das crianças atendidas, na perspectiva do desenvolvimento de uma parceria a ser estabelecida entre educador e pais.

Uma terceira etapa do projeto promoveu a organização de estágios de formação no Canadá para 12 educadores selecionados entre os participantes do grupo de 30 profissionais e dos projetos de "demonstração". Esse 
grupo recebeu uma formação intensiva de 60 horas sobre os temas: delinquência juvenil, crianças e adolescentes em situação de risco, intervenção em meio natural, uma Polícia voltada para a atuação junto à infância e adolescência, profissionalização e inserção no mercado de trabalho de indivíduos em dificuldades, crianças vitimizadas, programas de prevenção e os Tribunais da Juventude no Canadá. Ao retornarem, esse grupo organizou uma comunicação oral através da qual relatou a experiência vivida no Canadá, fazendo os possíveis paralelos com a realidade brasileira.

\section{CONSIDERAÇÕES FINAIS}

O projeto de formação em Psico-Educação, realizado graças ao convênio entre o governo municipal e organizações da sociedade civil, teve uma repercussão importante a nível de seus participantes. A experiência ribeirãopretana, embora limitada, dá indícios da validade do modelo psicoeducativo para a formação de profissionais e para a organização dos meios de intervenção no Brasil.

Embora a Psico-Educação não seja revolucionária no sentido de oferecer soluções mágicas para os problemas de ordem psico-social, ela ofereceu instrumentos de reflexão e de sistematização da prática a ser desenvolvida no cotidiano das instituições, dimensão reconhecida e apreciada por todos os integrantes dos grupos de formação.

Durante as reuniões de avaliação do projeto, ressaltou-se com maior ênfase os aspectos da metodologia psicoeducativa tais como a integração de elementos teórico-científicos às intervenções, a possibilidade de avaliação concreta dos esforços relativos às intervenções, a análise e a organização dos meios de intervenção inerentes ao modelo psicoeducativo, a dimensão da "utilização educacional" dos eventos do cotidiano, a viabilidade de uma rede integrada e complementar de serviços à juventude e a necessidade de formação consistente para os educadores-monitores que "animam" o dia-a-dia dos serviços e programas de atendimento.

De modo geral, todos apontaram a impossibilidade de aplicar coerente e consistentemente o modelo da Psico-Educação, dado o período reduzido de formação recebida, apontando assim para a necessidade de prever mecanismos de formação continuada de educadores e multiplicadores dessa metodologia.

Evidentemente, o impacto maior, decorrente da formação, deve ser verificado a nível dos dois serviços que se submeteram ao projeto de demonstração. Contudo, a amplitude e a qualidade desses efeitos devem ser melhor avaliadas. Para além da boa aceitação do modelo da Psico-Educação pelos profis- 
sionais implicados nesses serviços, buscar-se-à de maneira mais aprofundada investigar os efeitos da formação sobre a qualidade da prática exercida e sobre o processo evolutivo das crianças e adolescentes beneficiados. Somente deste modo, poder-se-à afirmar sobre a conveniência desse modelo para com as nossas necessidades, pensando-o assim como alternativa válida para a formação de nossos educadores-monitores e a qualificação da atenção direta.

\section{REFERÊNCIAS BIBLIOGRÁFICAS}

HUTZ, C.; KOLLER, S.H. \& BANDEIRA, D.R. (1996) - Resiliência e vulnerabilidade em crianças em situação de risco. Coletâneas da ANPEPP vol. 1 (12), 79-86.

LE BLANC, M. (1995a) - Y a-t-il trop d'adolescents placés en internat aux centres jeunesse de Montréal? Revue Canadienne de Psycho-Éducation, vol. 24 (2), 93-120.

LE BLANC. M. (1995b) - Rapport No 5 in: ERIEDA: Équipe de recherche pour l'intervention expérimentale differéncielle auprès des adolescents en difficultés. Montréal: Universidade de Montréal.

LEBON, A. (1996) - La psychoéducation: la science du vivre-avec éducatif et thérapeutique. Conferência realizada na Associação Palas Athenas do Brasil. São Paulo.

LEMAY, L. (1996) - Les jeunes en difficulté d'adaptation et les jeunes à risque (mimeo). Documento de trabalho do Centro de Psico-Educação do Québec: Canadá.

MENDES, E.G. \& COSTA, A.C.G. da (1994) - Das necessidades aos direitos. São Paulo:Malheiros Editores.

RENOU, M. (1989) - La psychoéducation: une perspective historique. Revue Cnadienne de Psycho-Éducation, vol. 18 (2), 63-88.

RENOU, M. (1991) - La psychoéducation: une critique rétrospective de la conception traditionnelle. Revue Canadienne de Psycho-Éducation, vol. 20 (2), 151-167.

TAKASHIMA, G.M.K. (1997) - O desafio ético dos mediadores frente as formas alternativas de famílias: o olhar sobre o público e o privado. Trabalho apresentado no I Congresso Brasileiro Sobre a Família. São Leopoldo, Rio Grande do Sul. 


\section{ABSTRACT}

This paper presents some aspects of a project developed by the municipal government and social entities, at Ribeirão Preto, SP, Brazil, with the aim to discuss the qualities and possibilities of social network support for the youth living in a risk situation. The project sought scientifics parameters to discussion, helping by the Centre de Psycho-Éducation du Québec (a canadian center of formation in University of Montreal), who has developed the psychoeducation approach.

Key words: social and personal risk, social network support, psycoeducation approach.

Palavras-chaves: risco pessoal e social, rede de apoio social, abordagem psicoeducativa. 